\title{
O Meio Técnico-Científico Informacional e os novos territórios metropolitanos ${ }^{1}$
}

\author{
Gerardo Silva*
}

\begin{abstract}
RESUMO. O artigo explora algumas hipóteses de trabalho sobre a questão da metrópole, o meio técnico-científico informacional e a globalização, na obra mais recente de Milton Santos. Trata-se de uma leitura que valoriza principalmente os elementos de reflexão que apontam para os processos constituintes da metrópole no mundo atual, marcado pela consolidação de uma forma perversa de globalização, hoje em crise. Explora-se também a perspectiva do Brasil e do continente latino-americano, uma condição do pensamento da qual o autor fez questão de nunca abrir mão.
\end{abstract}

PALA VRAS-CHA VE: Meio Técnico-científico informacional - Globalização Metrópole - Força dos pobres - Políticas do cotidiano - Crise financeira internacional.

A questão da metrópole no mundo contemporâneo torna-se relevante na medida em que ela passa a ocupar um lugar central no entendimento do processo de globalização e das transformações paradigmáticas que acompanham sua evolução. Como afirmam Lacourt \& Puissant (1999), a metrópole é o locus privilegiado dos novos arranjos sociais, técnicos e institucionais que se afirmam no marco dessa nova época. Trata-se, evidentemente, de uma metrópole que se constitui a partir de fatores específicos, tais como uma economia predominantemente de serviços, terceirizada e de alto conteúdo informacional. Por causa disso, a questão da metrópole (e da metropolização) volta a ser objeto de atenção, isto é, não como problema por causa do seu gigantismo, como anteriormente, mas como recurso a ser valorizado na sua dimensão produtiva e territorial.

\footnotetext{
${ }^{1}$ Uma versão preliminar deste trabalho foi apresentada e debatida no "Seminário Internacional MundoVix: Políticas do Comum", realizado na cidade de Vitória (ES), entre os dias 10 e 12 de deze mbro de 2008.

* Geógrafo. Doutor em Sociologia pelo Iuperj/UCAM. Pesquisador Associado do Laboratório Território e Co municação (LABTeC/UFRJ).
} 
$\mathrm{Na}$ literatura internacional, diversos autores têm problematizado a constituição das cidades globais e seus vínculos com as redes de informação e comunicação de abrangência mundial (cf. Castells, 1989; Sassen, 1991; [1994] 1998; Borja \& Castells, 1997). No Brasil, o esforço predominante tem sido o de estabelecer um diálogo crítico com essa literatura, em particular com seus aspectos mais apologéticos, destinados a se transformar, no melhor dos casos, em “idéias fora do lugar" (cf. Compans, 1999; Arantes et al., 2000; Ferreira, 2003). Contudo, o debate permanece aberto, e os desafios que a globalização impõe à metrópole continuam em pauta - sobretudo quando, nas atuais circunstâncias, a globalização neoliberal se encontra em crise. A seguir, avançamos algumas hipóteses de trabalho sobre a metrópole e a globalização contidas na obra mais recente de Milton Santos, que, tanto no plano conceitual quanto empírico, captura elementos gerais dessa relação e também coloca em relevo aspectos específicos da metrópole brasileira e latino-americana.

\section{A metrópole e o meio técnico-científico informacional}

Em uma entrevista publicada na revista Caramelo, em 1994, Milton Santos definia a metrópole como o "lugar do comando" e também como "o lugar onde é possível viver com sofisticação". ${ }^{2}$ Assim, se por um lado ele enxergava a metrópole como território das hierarquias e das decisões - no sentido clássico da definição de metrópole, pelo menos deste lado do Atlântico - pelo outro, visualizava um aspecto dinâmico e potente percebido como sofisticação: "Uma sofisticação", agregava, "que, todavia, não é o resultado de uma exclusão, mas de uma possibilidade ampla”. Desse modo, Milton Santos não apenas nos convidava a pensar a metrópole em um sentido qualitativo (além de quantitativo), como também afirmativo, isto é, como território de constituição de (outros) mundos possíveis.

O que seja "viver com sofisticação" traz, evidentemente, um questionamento: o que devemos entender por "sofisticação"? Milton Santos

\footnotetext{
${ }^{2}$ Reproduzida em Maria Ângela Pere ira Leite, Encontros. Milton Santos, 2007.
} 
responde dizendo que se trata apenas de um critério de distinção, relativo a uma tipologia de atividades realizada em um tipo determinado de centro, que se caracteriza pela sua morfologia técnico-científica e informacional, e que ele chama, mais concretamente, de "meio técnico-científico informacional". "Introduzindo a noção de meio técnico-científico", diz o autor, "eu introduzo uma diferença na constituição material dos objetos que formam a cidade e que trazem uma diferença no comportamento atual e no comportamento possível", e agrega: “O planejamento é uma ação política que supõe mudanças de comportamento. Não posso imaginar que vou planejar apenas fazendo uma ponte, construindo ou não um túnel, ou decidindo que aqui ou ali se fará uma torre. Isto não basta, porque a cidade tem gente dentro" $(1994$, p. 100).

O meio técnico científico informacional, portanto, é o que incita, na metrópole contemporânea, um comportamento diferente e "sofisticado", que se traduz, segundo Milton Santos, em um grau maior e mais avançado de inteligência produtiva: "Aquilo que no mundo atual é feito com maior rentabilidade, com maior produtividade, com maior eficácia, é feito nesse meio" (p. 91). Dois fenômenos abonam o desenvolvimento dessa camada técnicocientífica informacional: a expansão das formas de organização do trabalho vinculadas aos serviços e o aumento da participação do trabalho intelectual. Isto porque, como ele mesmo afirma em Técnica, Espaço e Tempo (1996), a produção material diminui em benefício da produção não material (sic). Assim, é preciso tomar consciência de uma nova época na qual os fluxos de informação e a percepção da simultaneidade - inclusive em escala global - tornam-se elementos estratégicos da constituição da metrópole.

Em uma nova entrevista de 2000, Milton Santos reafirma a importância do meio técnico científico informacional, porém fazendo questão de lembrar que no trabalho há sempre uma parcela técnica e uma parcela política: “A parcela técnica oferece a possibilidade nua de fazer e a parcela política atribui valor a esse fazer" (2000b, p. 36). Há, portanto, nesse meio, um determinante subjetivo que não se deixa aprisionar pela objetividade da técnica, que é normativa: "Meu trabalho é normatizado pela técnica, mas o é apenas em termos de performance e 
do output estatístico. Não há objetividade quando a questão é o valor. Aqui, o problema é político. Nosso problema é entender o uso da técnica, para aprimorarmos a consciência de nossa situação e melhorarmos a nossa condição cidadã" (p. 37).

Ora, sem chegar a explicitá-lo ainda (há de fato uma tendência constante, na obra de Milton Santos, a problematizar as dinâmicas sociais e territoriais em termos dialéticos, mesmo quando reconhece que a questão do valor é uma questão política), entender o uso da técnica para melhorar a condição cidadã, como ele afirma, significa reconhecer a importância das Novas Tecnologias da Informação e da Comunicação (NTICs) na constituição da metrópole, em particular, da metrópole como meio técnico-científico informacional. As NTICs, com efeito, têm sido (e continuam sendo) um elemento revolucionário das transformações sociais, políticas, culturais e institucionais do mundo contemporâneo, e não apenas um instrumento do comando capitalista ${ }^{3}$. Como afirmam Michael Hardt e Antonio Negri em Império (2002), hoje, a informatização da produção e da sociedade de um modo geral assinalam a emergência de "uma nova maneira de tornar-se humano (...) [na qual] é preciso inventar o que Pierre Lévy chama de antropologia do ciberespaço" (p. 310).

\section{Por uma outra Globalização}

Antes de voltarmos sobre a segunda parte da questão da metrópole e o meio técnico científico informacional, é importante nos determos um pouco na reflexão de Milton Santos em torno do processo de globalização. Aliás, diga-se de passagem, esse debate nos envolve há pelo menos três décadas, até a recente crise financeira internacional em que, pela primeira vez, começamos a enxergar esse processo despido de sua roupagem de modernização conservadora ou neoliberal. Em Por Uma Outra Globalização. Do pensamento único à consciência universal, ensaio publicado em 2000, o autor trata do fenômeno da globalização como

${ }^{3}$ Esse primeiro reconhecimento "negativo" do papel da NTICs contrasta, entretanto, com a afirmação posterior: "Os novos instrumentos [tecnológicos], pela sua própria natureza, abrem possibilidades para sua disseminação no corpo social, superando as clivagens socioeconômicas existentes" (Por uma Outra Globalização, 2000, p. 164). 
fábula, como perversidade e como possibilidade aberta ao futuro de uma nova civilização planetária - segundo as palavras de Maria da Conceição Tavares na apresentação do livro ${ }^{4}$.

$\mathrm{Na}$ globalização como fábula, o que nos é colocado é o problema ideológico do processo e suas promessas de redenção pelo mercado. Tratar-se-ia da imposição de um discurso único que se alimenta da produção de imagens e imaginários do mercado global, como vetor de integração das populações e suas culturas e territórios, criando a miragem de um novo regime de modernização sob comando capitalista. O mito da aldeia global, diz o autor, faz crer que fazemos parte de um mundo de fronteiras abertas, quando na verdade assistimos a novas formas de compartimentação neo-soberanistas dos territórios, através de blocos regionais e regionalismos exacerbados de todo tipo. Mesmo o discurso do Estado mínimo vai por água abaixo quando é preciso assistir financeiramente às grandes empresas multinacionais que precisam de ajuda para consolidar seus negócios em outros países.

$\mathrm{Na}$ globalização como perversidade, são apresentadas as mazelas associadas a esse processo. Uma onda de desemprego e precarização das condições de trabalho, além dos males espirituais, egoísmos, cinismos e corrupção, revelam, segundo Milton Santos, a perversidade sistêmica que está na raiz desse processo e que guarda íntima relação "com a adesão desenfreada aos comportamentos competitivos que atualmente caracterizam as ações hegemônicas" (p. 20). A contínua fragmentação dos laços sociais e das redes de solidariedade produtiva - e dos territórios da metrópole, como ele mesmo constatou em outras obras para o caso de São Paulo - constitui o modo de afirmação e reprodução do poder global, com sua enorme seqüela de pobreza e miséria segregada, principalmente nas periferias urbanas. A globalização como perversidade, enfim, é a promessa da fábula e do mito da aldeia global transformada em parâmetro único do horizonte político.

Contudo, afirma o autor, podemos pensar que as mesmas bases técnicas que sustentam o grande capital para construir a globalização perversa podem

\footnotetext{
4 A resenha feita por Ana Clara Torres Ribeiro na Revista Brasileira de Estudos Urbanos $e$ Regionais (2000) também destaca esse as pecto fundamental do liv ro.
} 
igualmente servir a outros objetivos, em particular quando colocadas ao serviço de outros fundamentos sociais e políticos. Uma outra globalização é possível, com efeito, quando podemos verificar, tanto no plano teórico quanto no empírico, a emergência e o fortalecimento de fenômenos sociais e políticos que, no mesmo plano de estabelecimento dos processos hegemônicos, questionam profundamente sua racionalidade. Um desses fenômenos, segundo Milton Santos, é a enorme mistura de povos, raças, culturas, gostos e estilos que se produz em todos os continentes, constituindo uma sóciodiversidade historicamente mais significativa que a biodiversidade (sic!). Vinculado a isso, há uma crise da cultura de massas que constituía uma poderosa matriz de controle nas sociedades industriais. $\mathrm{O}$ fenômeno emergente mais importante, entretanto, é a capacidade de outros usos possíveis das tecnologias da informação:

As famílias de técnicas emergentes com o fim do século XX combinando informática e eletrônica, sobretudo, oferecem a possibilidade de superação do imperativo da tecnologia hegemônica e paralelamente admitem a proliferação de novos arranjos, com a retomada da criatividade. Isso, aliás, já está se dando nas áreas da sociedade em que a divisão do trabalho se produz de baixo para cima. Aqui, a produção do novo e o uso e a difusão do novo deixam de ser monopolizados por um capital cada vez mais concentrado para pertencer ao domínio de maior número, possibilitando afinal a emergência de um verdadeiro mundo da inteligência. Desse modo, a técnica pode voltar a ser o resultado do encontro do engenho humano com um pedaço determinado da natureza - cada vez mais modificada -, permitindo que essa relação seja fundada nas virtualidades do entorno geográfico e social, de modo a assegurar a restauração do homem na sua essência" (2000a, p. 165).

Por último, Milton Santos acredita que a perspectiva de uma outra globalização também abre a possibilidade de um novo discurso, de uma nova meta-narrativa ou grande relato. Não é o fim da história, portanto, que está em jogo nessa profunda transformação do mundo contemporâneo, mas seu início ("A história apenas começa"). Se, no passado, o ecúmeno era formado de frações separadas ou pouco relacionadas do planeta, agora o movimento do mundo revela uma grande interdependência das economias, dos governos e dos lugares. "A grande sorte dos que desejam pensar a nossa época é a existência de uma técnica globalizada, direta ou indiretamente presente em todos os lugares, e de uma 
política planetariamente exercida, que une e norteia os objetos técnicos. Juntas, elas autorizam uma leitura, ao mesmo tempo geral e específica, filosófica e prática, de cada ponto da Terra" (2000a, p. 171).

\section{A “dissolução" da metrópole}

Podemos voltar agora sobre a segunda parte da questão da metrópole e o meio técnico-científico informacional. Uma das características marcantes dessa nova condição produtiva vinculada às NTICs é sua enorme capacidade de difusão social e territorial. Se por um lado ela é capaz de instituir uma possibilidade ampla de sofisticação das relações sociais e produtivas da metrópole, por outro ela carrega um poder de difusão territorial formidável, tornando possível o acoplamento instantâneo das regiões e das cidades em uma vasta rede de informações. A metrópole torna-se, desse modo, onipresente, como meio técnicocientífico informacional que se alimenta da inteligência dos fluxos mais do que propriamente das benesses dos lugares: "Trata-se, assim, de uma verdadeira 'dissolução da metrópole', condição, aliás, de funcionamento da sociedade econômica e da sociedade política [no mundo atual]" (1996, p. 156).

Uma das conseqüências imediatas dessa "dissolução da metrópole", segundo o autor, é que as questões de centro e periferia e das regiões polarizadas, tal como colocadas em outros momentos da história, ficam ultrapassadas. Há, com efeito, um tornar-se centro da periferia e vice-versa (Milton Santos prefere falar de uma "centralidade da periferia"). Uma nova topologia da rede urbana, mais aberta e flexível, vem substituir as antigas morfologias do lugar central: "A história brasileira já mostra uma redistribuição da urbanização concentrada. Hoje, existem dezesseis cidades com mais de um milhão de habitantes, a metropolização já está se redistribuindo. E as próprias cidades médias nascem como cogumelos. Temos que aproveitar a tendência, mas imprimindo-lhe um conteúdo social" (2000b, p. 59, destaque nosso).

Um amplo processo de diferenciação caracteriza essa difusão territorial da metrópole, instituindo possibilidades de inovação onde elas praticamente não 
existiam. Às antigas "vocações" locais, normalmente assimiladas de "cima para baixo", superpõem-se agora competências específicas de cunho técnicocientífico informacional, cuja característica principal é a de serem constituídas de "baixo para cima". Trata-se de redes de cooperação horizontal resultantes da "coexistência do diverso" (sic) em cada território. Por sua vez, esse processo de diferenciação é acompanhado, segundo Milton Santos, de um processo de complexificação urbana, no sentido de um adensamento das relações sociais e da organização um tanto difusa das novas formas de trabalho "segundo uma vasta tipologia de produções”(1996, p. 142).

Tanto os processos que hoje afirmam a constituição da metrópole, quanto os que conjuram sua "dissolução", possuem, na obra do autor - e é importante que se diga - antecedentes no seu próprio posicionamento sobre a questão da urbanização e da população urbana no Brasil, que somente em período muito recente superou a população rural $^{5}$. Para Milton Santos, com efeito, a cidade sempre foi o lugar do êxodo que possibilitou, mesmo em condições extremamente difíceis, uma fuga das relações escravocratas predominantes no meio rural. Além do mais, a cidade sempre foi vista pelo autor como espaço de resistência e de política:

... a cidade é multidimensional. A cidade do campo é [apenas] um pouco mais que unidimensional, porque nela avultam determinações que são verticais. Mas a grande cidade não. Ela reúne pessoas das mais diversas origens, dos mais diversos níveis de instrução, de riqueza, de entendimento. Constitui-se em um lugar em que é possível uma mistura de interpretações mais ou menos corretas do mundo, do país e do próprio lugar. Há uma enorme riqueza de perspectivas. A vizinhança obriga as pessoas a se compararem e a se perguntarem sobre as suas diferenças, seja ela próxima ou distante. Essa já é uma indagação de natureza política. E ainda que nem sempre seja possível às pessoas uma interpretação sistêmica, há um questionamento e um desejo de ultrapassar a própria situação (2000b, p. 60, destaques nossos).

\footnotetext{
${ }^{5}$ No Brasil, a população urbana somente superou a rural em 1970; fechou o século em torno de $80 \%$, e segue aumentando.
} 


\section{A força dos pobres}

"A força dos pobres é a força da transformação e da mudança". Com essas palavras, Milton Santos conceitua o lugar dos pobres na sociedade brasileira e latino-americana de um modo geral. Ao longo de toda sua obra ele outorgou essa centralidade à força dos pobres contra os discursos da vitimização ou da aceitação passiva das relações de poder. Os pobres resistem e lutam desde o cotidiano da sua condição - que o autor chama de "espaço banal" ou de "pragmática da existência" - quando eles interpretam, corretamente, que essa condição nada tem de natural ou sobrenatural. Os pobres, com efeito, lutam contra a pobreza: "Isto, sem dúvida, pode se manifestar pela violência. Mas a violência é também uma forma de discurso, um discurso, aliás, peculiar na sociedade em que vivemos. Em suas manifestações mais agudas, não é anormal que a sociedade urbana aponte para as desordens produzidas pela história contemporânea. Mas ela também aponta para uma vontade de entendimento, pedindo que se explique o que é que está se passando, de modo a alicerçar um entendimento que produza sentido" (2000b, p. 60-61).

Ora, se a força dos pobres é a força da transformação e da mudança, como ela se vincula com o meio técnico-científico informacionale com as dinâmicas de constituição e "dissolução" da metrópole? Parece-me que a resposta do autor a essa importante questão possa ser dividida em três partes. A primeira, a partir do reconhecimento, agora sim explicitamente, do valor das NTICs e da capacidade de apropriação dessas tecnologias por parte dos pobres, tanto no que diz respeito ao trabalho (seja este formal ou informal), quanto no que se refere às múltiplas “outras" maneiras de auferir rendas. Vinculada a essa capacidade de apropriação temos também a recuperação e disseminação das culturas populares, que, segundo Milton Santos, encontram novos canais de expressão, mixagem e valorização ${ }^{6}$.

\footnotetext{
${ }^{6}$ Tal como acontece com o Tecnobrega na periferia de Belém (PA), que não apenas ressignifica uma expressão musical típica da cidade (o Brega) ao as sociá-la à cultura digital (o Tecno), como também inova no próprio negócio da música (cf. Lemos e Castro, 2008).
} 
A segunda parte é a mais controversa. Haveria, de acordo com o autor, uma força dos pobres como força reativa vinculada ao consumo. A expansão do consumo que acompanha o processo de urbanização funcionaria como uma faca de do is gumes para o desenvolvimento capitalista. Se, por um lado, essa expansão dos mercados encontraria novas oportunidades de negócios, por outro, evidenciaria as enormes diferenças de acesso a esses mercados por parte dos diferentes grupos sociais. Isso criaria um desconforto progressivo entre os pobres, expostos a um universo de consumo sem possibilidades plenas de participação na verdade, com possibilidades extremamente limitadas. Esse desconforto, entretanto, que em certas ocasiões transforma-se em atos de violência, traduz-se também em conscientização e questionamento dos modelos sociais e econômicos vigentes.

A terceira parte da resposta está mais embasada na perspectiva do desenvolvimento de uma solidariedade não-contratual (nem cristã!) que diferencia os pobres de outros grupos sociais. Trata-se de uma solidariedade produtiva mediada pelos afetos e pelas relações de confiança que se estabelece $\mathrm{m}$ nas comunidades e nas periferias. Sem essa solidariedade nenhuma forma de resistência seria possível. Acontece, entretanto, que esse tipo de solidariedade constitui a base da vida em comum da sociedade em geral, e não apenas dos pobres. Na socied ade burguesa ou da representação, es sa solidariedade é solapada por um arcabouço institucional que retira as condições da sua autonomia. Nesse sentido, Milton Santos identifica na luta dos pobres um elemento universal da luta pela emancipação. Não caberia a menor dúvida, portanto, pensarmos agora que a sofisticação referida na nossa fala inicial seria, na verdade, a força dos pobres e sua enorme inteligência para compor as condições de produção da metrópole brasileira.

\section{A política do cotidiano}

O último capítulo de Por Uma Outra Globalização chama-se "A transição em marcha”, e nele são esboçadas as alternativas políticas que se abrem à nova era da 
globalização, desenvolvimento das metrópoles e meio técnico-científico informacional. Trata-se de uma transição, afirma Milton Santos, porque o novo ainda está por ser construído. Se a globalização apresentou-se principalmente como fábula e como perversidade, é preciso potencializar as condições que fazem dela também uma oportunidade. Se até agora predominaram as determinações hierárquicas do processo ("de cima para baixo", sob comando das grandes empresas), cada vez mais a força dos "excluídos" tornam essas determinações inviáveis, impondo uma lógica mais colada nos territórios e suas dinâmicas sociais ("de baixo para cima", mais horizontal na sua prática de organização produtiva). ${ }^{7}$

Dentre o conjunto de questões e palavras de ordem que são levantadas, destacam-se as que dizem respeito à política do cotidiano, ou seja, as que se referem às "práticas de vida e existência de todos". Para Milton Santos, com efeito, o papel dos pobres na produção do presente e do futuro se define na "vida concreta da maioria das populações", onde é preciso inventar a cada dia "formas inéditas de trabalho e de luta". Instaura-se dessa forma uma política de tipo novo, que não deve ser confundida com uma política institucional, posto que ela se reporta diretamente ao cotidiano:

$\mathrm{Na}$ realidade, uma coisa são as organizações e os movimentos estruturados e outra coisa é o próprio cotidiano como um tecido flexível de relações, adaptável às novas circunstâncias, sempre em movimento. A organização é importante, como o instrumento de agregação e multiplicação de forças afins, mas separadas. Ela também pode constituir o meio de negociação necessário a vencer etapas e encontrar um novo patamar de resistência e de luta. Mas a obtenção de resultados, por mais compensadores que pareçam, não deve estimular a cristalização do movimento, nem encorajar a repetição de estratégias e táticas. Os movimentos organizados devem imitar o cotidiano das pessoas, cuja flexibilidade e adaptabilidade the asseguram um autêntico pragmatismo existencial e constituem a sua riqueza e fonte principal de veracidade (2000a, p. 134, destaques nossos).

\footnotetext{
7 "Na divisão do trabalho por cima cria-se uma solidariedade gerada de fora e dependente de vetores horizontais cimentados no território e na cultura locais. Aqui, são as relações de proximidade que avultam, este é o domínio da flexibilidade tropical com a adaptabilidade endógena. A cada movimento novo, há um novo reequilíbrio em favor da sociedade local e regulado por ela" (2000a, p. 146).
} 
$\mathrm{Na}$ metrópole, a densidade e as relações de vizinhança (entendidas como relações de proximidade física) são constitutivas de solidariedades e vínculos produtivos específicos, dos quais é composta a sua principal riqueza - o "tecido flexível de relações, adaptável às novas circunstâncias, sempre em movimento", como destacado na citação acima. Não se trata, portanto, de uma política do cotidiano que recusa a transformação, que se entrincheira na dimensão local para se opor à globalização, muito pelo contrário. O local da metrópole é a sua capacidade de afirmar uma outra globalização que sirva aos processos de emancipação em um patamar mais elevado, planetário. Como ele mesmo afirma: "a história do homem sobre a Terra dispõe afinal de condições objetivas, materiais e intelectuais, para superar o endeusamento do dinheiro e dos objetos técnicos e enfrentar o começo de uma nova trajetória" (2000a, p. 173).

\section{A globalização e a crise financeira internacional (à guisa de conclusão)}

No momento em que finalizamos este artigo, a crise econômica internacional que decreta o fim do neoliberalismo encontra-se no seu apogeu. Entidades financeiras de porte mundial solicitam ajuda aos estados de origem, sob o risco de quebrar e alastrar para o desemprego, a pobreza e a miséria, milhões de pessoas no mundo inteiro, sem exceção. Fundos públicos tantas vezes negados para projetos sociais são agora utilizados para salvar a economia de mercado ou o que restou dela. Ninguém mais acredita (se é que alguma vez acreditou) que as "falhas de mercado" sejam apenas problemas técnicos de teoria monetária. Elas representam seu limite estrutural, ou seja, a falência do mercado, porque as forças que operam tais falhas estão sempre fora de alcance de suas normas e procedimentos. Trata-se dos limites à "globalização perversa", na conceituação de Milton Santos.

Em Por Uma Outra Globalização, entretanto, encontramos uma antecipação ainda mais precisa dos fatores capazes de desencadear a crise:

Nas condições atuais de economia internacional, o financeiro ganha uma espécie de autonomia. Por isso, a relação entre a finança e a produção, entre o que agora se chama economia real e o mundo da finança, dá lugar àquilo que Marx chamava de loucura especulativa, fundada no 
papel do dinheiro em estado puro. Este se torna o centro do mundo. É o dinhe iro como, simplesmente, dinheiro, recriando seu fetichismo pela ideologia. O sistema financeiro descobre fórmulas imaginosas, inventa sempre novos instrumentos, multiplica o que chama de derivativos, que são formas sempre renovadas de oferta dessa mercadoria aos especuladores. O resultado é que a especulação exponencial assim redefinida vai se tornar algo indispensável, intrínseco, ao sistema, graças aos processos técnicos da nossa época. É o tempo real que vai permitir a rapidez das operações e a volatilidade dos assets. E a finança move a economia e a deforma, levando seus tentáculos a todos os aspectos da vida. Por isso, é lícito falar de tirania do dinheiro (2000a, p. 44, destaque nosso).

Será que a crise econômica internacional vem para acabar com a tirania do dinheiro? A julgar pelas medidas que estão sendo tomadas nos diferentes países e, principalmente, nos Estados Unidos da América, certamente não. Ao que parece, estamos substituindo uma tirania dura por uma tirania branda, na qual uma vultosa injeção de dinheiro público no mercado "para minimizar a crise" (sic) será acompanhada de uma maior regulação e controle das operações financeiras por parte dos Estados. Contudo, haverá mudanças significativas no funcionamento do sistema econômico mundial, posto que qualquer tipo de unilateralismo (econômico, geopolítico, cultural, ambiental) tornou-se hoje inviável. A globalização avançou a um ponto de não retorno, o que abona a tese de Milton Santos da necessidade de se começarem a pensar os problemas do Brasil em termos do mundo.

\section{Referências}

ARANTES, Otília et al. A Cidade do Pensamento Único: desmanchando consensos. Petrópolis: Vozes, 2000.

BORJA, J.; CASTELLS, M. Local y Global. La gestión de las ciudades en la era de la información. Madrid: Taurus, 1997.

CASTELLS, Manuel. La Ciudad Informacional. Tecnologias de la información, reestructuración económica y el proceso urbano-regional. Madrid: Alianza Editorial,1989. 
COMPANS, Rose. "O paradigma das global cities nas estratégias de desenvolvimento local”. In: Revista Brasileira de Estudos Urbanos e Regionais, n.1. ANPUR, Campinas, maio de 1999.

FERREIRA, João Sette Whitaker. "São Paulo: o mito da cidade-global". São Paulo: FAUUSP, 2003 (Tese de Doutorado).

LACOURT C.; PUISSANT, S. La Metropolisation. Croissance, diversité, fractures. Paris: Anthropos, 1999.

LEMOS, R.; CASTRO, O. Tecnobrega. O Pará reinventando o negócio da música. Rio de Janeiro: Aeroplano, 2008.

NEGRI, A.; HARDT, M. Império. Rio de Janeiro: Record, 2002.

LEITE, Maria Ângela F. P. (org.); Encontros. Milton Santos. Rio de Janeiro: Azougue Editorial, 2007.

SANTOS, Milton. Técnica Espaço Tempo. Globalização e meio técnicocientífico informacional. São Paulo: Hucitec, 1996.

Por uma outra globalização. Do pensamento único à consciência universal. Rio de Janeiro: Record, 2000a.

Território e Sociedade. Entrevista com Milton Santos. São Paulo: Editora Fundação Perseu Abramo, 2000b.

SASSEN, Saskia. The Global City. New York, London, Tokio. Princeton: Princeton University Press, 1991. 1998).

As Cidades na Economia Mundial. São Paulo: Studio Nobel, [1994] 